\title{
Epistemology, Assessment, Pedagogy: Where Learning Meets Analytics in the Middle Space
}

\author{
Simon Knight, Simon Buckingham Shum \\ Knowledge Media Institute \\ Karen Littleton \\ Centre for Research in Education \& Educational Technology \\ The Open University, UK \\ simon.knight@open.ac.uk
}

\begin{abstract}
Learning Analytics is an emerging research field and design discipline that occupies the "middle space" between the learning sciences/educational research and the use of computational techniques to capture and analyze data (Suthers \& Verbert, 2013). We propose that the literature examining the triadic relationships between epistemology (the nature of knowledge), pedagogy (the nature of learning and teaching), and assessment provide critical considerations for bounding this middle space. We provide examples to illustrate the ways in which the understandings of particular analytics are informed by this triad. As a detailed worked example of how one might design analytics to scaffold a specific form of higher order learning, we focus on the construct of epistemic beliefs: beliefs about the nature of knowledge. We argue that analytics grounded in a pragmatic, socio-cultural perspective are well placed to explore this construct using discourse-centric technologies. The examples provided throughout this paper, through emphasizing the consideration of intentional design issues in the middle space, underscore the "interpretative flexibility" (Hamilton \& Feenberg, 2005) of new technologies, including analytics.
\end{abstract}

Keywords: Learning analytics, epistemology, pedagogy, educational assessment, discourse analytics, social learning analytics

\section{INTRODUCTION}

Assessment is one area where notions of truth, accuracy and fairness have a very practical purchase in everyday life. (Williams, 1998, p. 221)

Assessment sits at the heart of learning, but is hugely controversial. This is directly relevant to learning analytics, because - we argue - learning analytics implicitly or explicitly promote particular assessment regimes. Presently, many education systems are predicated on assessment regimes seeking to accredit knowledge and skills gained by students through formal assessments - often exam based. Proponents of such exams suggest they are the fairest way to assess competence and learning under controlled, reliable conditions. Assessment, pedagogy and curriculum are fundamentally related (Harlen, 2007), but many regimes of what has come to be termed "high stakes" testing are criticized. For example, standardized assessments, including the Programme for International Student Assessment (PISA), American Standardized Assessment Tests (SATs), and English National Curriculum Assessments (Sats) face myriad problems. Not least among these is that the exams are criticized comprehensively (e.g., Davis, 1999; Gardner, 2011; Hopmann, Brinek, \& Retzl, 2007) on two key validity criteria: for failing to represent adequately the types of problems people are likely to face in their everyday lives (external 
validity), and that they fail to represent an adequate conceptualization of what it means to know - of what knowledge is (internal validity). The latter claim is that while assessments clearly measure something, a good grade does not necessarily reflect mastery (Davis, 1999). These fundamental issues are highlighted in a significant body of research (e.g., Davis, 1999; Gardner, 2011; Hopmann et al., 2007), and one of the objectives in writing this paper is to clarify the implications of these issues for the Learning Analytics community.

In this paper, Section 2 considers the relationship between assessment systems and the sorts of epistemic challenges students might encounter. Section 3 introduces the concept of epistemic beliefs, and Section 4 goes on to discuss the relationships between learning analytics, and the triad of epistemology, pedagogy, and assessment. Section 4.2.1 then introduces pragmatic, socio-cultural approaches to learning analytics, which we suggest are well placed to probe or assess facets of learning that other learning analytics may not adequately address. To exemplify this argument, we draw a parallel between the psychometric measurement of epistemic beliefs and high stakes testing regimes (Section 5). The parallel is expanded in Section 6, which offers a detailed example of how our own orientation might make design decisions in the Learning Analytics "middle space." We conclude by reflecting on some broader ways in which these considerations might play out in various analytic approaches, maintaining the significance of the triad throughout.

\section{WHY WORRY ABOUT EPISTEMOLOGY?}

A primary concern of this paper is the relationship between epistemology, pedagogy, and assessment. Epistemology is the philosophical study of what knowledge is, and what it means for someone to "know" something. Central to the field of epistemology are questions regarding the nature of truth, the nature of justification, and types of knowledge, e.g., knowing how (skills) or knowing that (facts). Whatever "knowledge" is, "it is uncontroversial, pre-philosophically, that education aims at the imparting of knowledge: students are educated in part so that they may come to know things" (Siegel, 1998 , p. 20). Thus, pedagogy may in part be seen as the study of how to impart this knowledge to students - the science and development of approaches to teaching and learning for knowledge. However, epistemology's relationship to the more familiar concepts of pedagogy and assessment is a topic of educational debate (Davis, 1999; Dede, 2008; Kelly, Luke, \& Green, 2008; Williams, 1998), and we will consider this in relation to learning analytics throughout this paper.

Harlen (2007) depicted a triadic relationship between pedagogy, assessment, and practice. Influenced by this, and Katz's (2000) description of "competency, epistemology and pedagogy: curriculum's holy trinity" we depict the triad as in Figure $1 .^{1}$

In this picture, epistemology could be seen as driving assessments aimed at uncovering student knowledge, and driving pedagogy to build high quality knowledge to that end. In this view, assessment is targeted at the learning of high-level knowledge - it is assessment for learning. However, these relationships are not fixed; neither pedagogies nor epistemologies necessarily entail the other (Davis \& Williams, 2002) (although they may implicate). Furthermore, as we will explore in this paper,

1 We could also introduce the notion of "folk psychology" as a mediating factor between a teacher's views on knowledge and pedagogy; for example, if we hold that some (particular) children will never learn $\mathrm{x}$, we are unlikely to attempt to teach it (a pedagogical "move") regardless of our epistemological stance regarding the nature of " $x$ " (Olson \& Bruner, 1996). However, in that paper, Olson and Bruner implicate epistemology in a number of their points regarding "folk pedagogy." 
assessment is always concerned with devising proxies for "knowledge," around which there are philosophical (epistemological) and methodological issues. Some epistemological stances hold that it is not possible to "map" the knowledge that students hold onto their responses in assessments in reliable and valid ways. This issue is further confounded by the methodological limitations of all assessment methods, and by extension learning analytics. The adequacy of analytic techniques to illuminate learning should be open to enquiry.

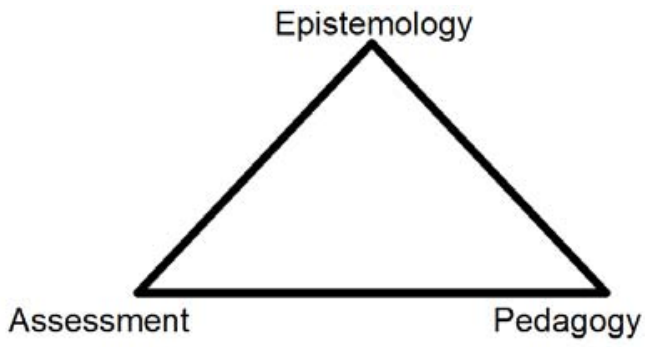

Figure 1. The Epistemology-Assessment-Pedagogy triad

The situation is, therefore, a complex one - which facet of the triad has primacy over the others is not clear in either theory or practice, and may be dynamic according to need and circumstance. However, relationships between the three can certainly be identified, and throughout this paper, we draw out some of these with respect to learning analytics - which may be conceptualized as a component of assessment. Furthermore, we suggest that, although the relationship may not be a necessary one, assessment regimes do implicate particular epistemological stances. Our position is that attention to this middle space - bounded by epistemology, assessment, and pedagogy - provides key considerations for the design of learning analytics.

Consider the following example from Denmark to illustrate the argument that, implicitly or explicitly, epistemological assumptions fundamentally shape pedagogy and assessment, and hence, the kinds of learning analytics that one deploys to achieve those ends. In Denmark, a pilot project was conducted permitting the use of the Internet (but not communication sites) to support students in five schoolleaver subject exams. ${ }^{2}$ This made it possible to set questions requiring the use of multimedia and individual Internet searches where students may be given unfamiliar resources and permitted to source information for themselves from the Internet. For example, a student might be asked to write about a poet whom they have not studied (preventing rote learning), having been provided with a poem, plus another by a contemporary, a short biography, and perhaps an image from the time. Thus, while Danish students are expected to evidence "knowledge-that" - knowledge of facts - they must also exhibit a higher level of "knowing-how," for example around information processing, synthesis, and metacognitive abilities - which remain unassessed in countries restricting access to external resources that might enhance the student's capability. While this, of course, remains a controlled assessment context, the example illustrates how even within a system reliant on exams, those exams might be conducted on a rather different epistemological grounding. Assessment regimes such as the Danish example may be taken to reflect a holistic epistemology in which how one comes to know is as important as what one comes to know, and in which it makes little sense to pick out individual tokens of knowledge in decontextualized ways (Davis \& Williams, 2002; Davis, 1998, 2005; Katz, 2000).

2 Steen Lassen (a Danish Education Minister) on the piloting of Internet access in exams: http://vimeo.com/8889340 subsequently adopted by some Danish universities (Cunnane, 2011). 
We can contrast such assessments with high stakes testing regimes whose construct validity and external validity have been questioned. For instance, Davis $(1999 ; 2006)$ argues that such instruments neither assess those facets of learning they set out to test, nor those facets of learning that would likely be utilized in the everyday deployment of knowledge in any particular domain. Davis has argued that high stakes testing is inadequate for understanding learning, in so far as its construal of that learning is necessarily restricted by a desire for highly reliable metrics of success. As such, it must exclude the nuanced understanding of student meaning-making, the social context in which learning occurs, and how knowledge is constituted and enacted. He argues that this, as opposed to acquisition, is the appropriate way to talk about knowledge. Davis draws on notions of situated cognition (Salomon, 1996) and socio-cultural approaches (Säljö, 1999) - particularly Säljö’s "Literacy, Digital Literacy and Epistemic Practices: The Co-Evolution of Hybrid Minds and External Memory Systems" (Säljö, 2012). Säljö highlights that:

From the learning and literacy points of view, such tools [memory aides and knowledge management systems of various sorts] imply that users' knowledge and skills, as it were, are parasitic on the collective insights that have emerged over a long time and which have been entered into the instrument in a crystallized form: algorithms, grammatical rules and concepts, etc. The user will manipulate the artificial memory system in a number of ways in order to see what comes out of the processing that goes on in the machine. (Säljö, 2012, p. 14)

However,

Engaging with external memory systems thus requires familiarity with a varied set of epistemic practices that range from deciphering letters on a page through familiarity with meaning-making in relation to discourses and genres of texts and other media, to metaknowledge about how such resources may be used. (Säljö, 2012, p. 12)

Säljö makes an epistemological claim, specifically, a socio-cultural, pragmatist claim: that there are important literacies and practices to be mastered in learning; that those should themselves be objects of assessment; and language and discourse are critical filters on our grasp of the world. Such an epistemology has implications for how we teach, what we assess, and which analytics techniques might be deployed. "Success" can no longer be defined as a matter of regurgitating, unaided, the correct information in a two-hour exam. Such an epistemology also, we argue, offers a perspective on why even technologically advanced societies such as Denmark that assess knowledge in less abstracted, socially embedded ways, information seeking and processing via the Internet and search engines remains a significant challenge for students (UAGU, 2010, p. 15) Although the Internet provides wider access to information, information is not knowledge. Student engagement with information should consider both the kinds of knowledge that we might call transferable competencies or skills - including those higher order skills often known as metacognitive abilities - and more propositional or fact-based knowledge. In this context, we might consider information management and seeking not only as a means to an ends, but as a way to encourage interaction with a complex network of information. As argued by Tsai, as not only:

...a cognitive tool or a metacognitive tool; rather, it can be perceived and used as an epistemological tool. When the Internet is used as an epistemological tool for instruction, learners are encouraged to evaluate the merits of information and knowledge acquired 
(2014). Epistemology, Assessment, Pedagogy: Where Learning Meets Analytics in the Middle Space. Journal of Learning Analytics, 1(2), $23-47$.

from Internet-based environments, and to explore the nature of learning and knowledge construction. (Tsai, 2004, p. 525)

In this conception, learners are encouraged to think about the context, reliability, validity, certainty, and connectedness of knowledge.

To summarize, this section has argued that a consideration of epistemology is important to learning analytics in two related senses:

- The ways that we assess, the sorts of tasks we set, and the kinds of learning we believe to take place (and aim for) are bound up in our notions of epistemology. Learning analytics are not objective or neutral: data does not "speak for itself" but has been designed by a team who, implicitly or explicitly, perpetuate the pedagogical and epistemological assumptions that come with any assessment instrument.

- The Danish example shows concretely how epistemology relates to assessment regimes. When knowledge is seen as something that can only be evidenced in contextualized activity, and when it is embedded in one's physical and digital environment, the role of the Internet is redefined as a metacognitive tool that cannot be excluded in assessment.

These epistemological considerations foreground the quality of a student's enquiry processes as important, not just whether they get the right answer. An aspect of that enquiry process is epistemic beliefs - and it is to these that we will turn shortly.

Before we do so, we should note the importance of the whole triad in bounding the middle space of learning analytics, as defined by the programme chairs of the 2013 learning analytics conference:

In summary, although individual research efforts may differ in their emphasis, we believe that all research in Learning Analytics should address the "middle space" by including both learning and analytic concerns and addressing the match between technique and application. Advances in learning theory and practice are welcome, provided that they are accompanied with an evaluation of how existing or new analytic technologies support such advances. Advances in analytic technologies and methods are welcome, provided that they are accompanied with an evaluation of how understanding of learning and educational practices may be advanced by such methods. (Suthers \& Verbert, 2013, p. 2)

As noted earlier, it is our claim that epistemology is fundamental to the understanding of assessment, and that learning analytics fits in this scope. Furthermore, there is a bi-directional influence. Thus, design choices around assessments, often practical ones, may push towards particular epistemological stances, for example in the case of high stakes testing. In the other direction, sometimes explicitly epistemological stances, as in the Danish example, lead to particular forms of assessment being privileged. The role of learning here is also important; we have noted that the focus of pedagogy can be taken to be the bringing about of knowledge in students, as conceptualized by epistemology. However, practical considerations are again in play here, including the particular sorts of information privileged. Particularly pertinent is the role that we intend learning analytics to play in assessment: learning analytics that provides summative feedback is likely to relate to different types of learning, analytics, and outcome than learning analytics based on the provision of formative feedback. 
The "interpretative flexibility" of new technologies, including analytics, is high: when we consider appropriation of technology within particular social settings, we should be mindful of not falling into the trap of technological determinism (Hamilton \& Feenberg, 2005). As Crook and Lewthwaite (2010) note, our expectations for technology for transformative change should be mitigated by an understanding of those technologies in wider educational systems. Moreover, we should understand that technology's influence comes about through pedagogic change, not out of technology's direct effects (Crook \& Lewthwaite, 2010). Indeed, the epistemological stance taken in this paper is one well aligned with approaches that situate technology in its wider application, in non-deterministic ways (Oliver, 2011).

As noted above, the adequacy of analytic techniques to meet learning should be open to enquiry. This involves understanding the design trade-offs one is negotiating (intentionally or unintentionally) in developing and deploying technological solutions. This paper argues that this analysis - this bounding - fundamentally involves understanding epistemology, pedagogy, and assessment and their interrelationships in the context of learning analytics. In Section 6 we return to these considerations in the context of the example introduced below - that of epistemic cognition.

\section{EPISTEMIC BELIEFS}

One facet of students' dynamic interaction with the world of information relates to how they conceptualize the information needed to answer a question - their epistemic beliefs regarding the nature of the question and how it may be answered. The sorts of assessment, and pedagogy, to which students are exposed will shape the types of epistemic challenge they encounter in their education systems with a focus on "right answerism" and limited access to external epistemic resources offer fewer opportunities for challenging knowledge claims (Davis, 1999; Katz, 2000). This paper thus differentiates two related concepts:

1. Epistemology, which we introduced above, relates to the philosophical analysis and conceptualization of curriculum content and assessment for knowledge

2. Epistemic Beliefs, which we now introduce, relates to the intrapersonal, psychological conceptualizations that individuals hold regarding knowledge

Indeed, a key component of formative Assessment for Learning ( $\mathrm{AfL}$ ) may be the disambiguation of the epistemic requirements of questions - in terms of understanding the question, its context, and the knowledge required to answer the question (Black \& Wiliam, 2009). That is, AfL may play a crucial role in guiding a student's epistemic beliefs on the subject of the epistemological assumptions built into assessment systems themselves.

Table 1 indicates four dimensions of epistemic beliefs for which there is general agreement across the various models of belief. ${ }^{3}$ These dimensions are useful to consider in relation to student understanding of knowledge domains. For example, in the context of search engine tasks, "epistemological beliefs are a lens for a learner's views on what is to be learnt" (Bromme, Pieschl, \& Stahl, 2009, p. 8). In such tasks, student search activity may be analyzed using the dimensions in Table 1 (e.g., Mason, Ariasi, \& Boldrin, 2011), providing a lens onto students' understanding of their own learning, their task demands, and how they meet those demands.

3 See, for example, Schraw (2013) for a review of the multiple theoretical frameworks. 
Epistemic beliefs are thus one example of the type of construct that learning analytics may probe; however, they are also a particularly good example given their relationship to our everyday dealings with the world of information, and their relationship to pedagogy, assessment, and classroom practices (Hofer, 2001). Section 5 will discuss epistemic beliefs in relation to their measurement, but we shall first introduce some established approaches to pedagogy.

Table 1. Dimensions of epistemic belief (adapted from Mason, Boldrin, \& Ariasi, 2009, p. 69)

\begin{tabular}{|l|l|}
\hline Dimension & Description \\
\hline Certainty of knowledge & $\begin{array}{l}\text { The degree to which knowledge is conceived as stable or changing, } \\
\text { ranging from absolute to tentative and evolving knowledge }\end{array}$ \\
\hline Simplicity of knowledge & $\begin{array}{l}\text { The degree to which knowledge is conceived as compartmentalized or } \\
\text { interrelated, ranging from knowledge as made up of discrete and } \\
\text { simple facts to knowledge as complex and comprising interrelated } \\
\text { concepts }\end{array}$ \\
\hline Source of knowledge & $\begin{array}{l}\text { The relationship between knower and known, ranging from the belief } \\
\text { that knowledge resides outside the self and is transmitted, to the } \\
\text { belief that it is constructed by the self }\end{array}$ \\
\hline Justification for knowing & $\begin{array}{l}\text { What makes a sufficient knowledge claim, ranging from the belief in } \\
\text { observation or authority as sources, to the belief in the use of rules of } \\
\text { inquiry and evaluation of expertise }\end{array}$ \\
\hline
\end{tabular}

\section{OUR LEARNING ANALYTICS ARE OUR PEDAGOGY}

Buckingham Shum (2012) used the shorthand "our learning analytics are our pedagogy" to draw attention to the arguments set out in more detail above: that the types of analytic we chose to deploy, and the ways in which we deploy them implicate particular approaches to learning and assessment. This is particularly important given that any use of analytics will be in the context of a wider educational ecosystem, as Crook and Lewthwaite (2010) noted. It is this relationship between the types of analytic we deploy and our pedagogies that we now consider.

\subsection{Pedagogy and Analytics}

The relationship between learning analytics and pedagogy is important because they are both bound up in epistemology - what knowledge is. This section explicitly introduces the relationship between a number of established pedagogic approaches and learning analytics. These are not intended as comprehensive reviews, but rather as brief overviews of how the relationship between pedagogy and learning analytics might be conceptualized. The following section expands on some key ideas here, before moving on to explicate the core topic of this paper - a socio-cultural learning analytic - and one proposed instantiation of a learning analytic based on this approach.

\subsubsection{Transactional or instructionalist approach}

Transactional approaches hold that learning entails the transfer of knowledge from the knower 
(teacher) to the learner (student). They are characterized by a perspective on assessment in which success is "out there," assessable in the degree of correspondence between the claims that learners make, and the facts that they have been taught. Clearly there is a role for mastering facts in many curricula, and the technological ease with which these may be automatically assessed underlies their current dominance of learning analytics and automated assessment (formative and summative).

Analytics Implications: Learning analytics based on transactional approaches will tend to focus on simple metrics such as test scores, not requiring deeper analysis of more complex artefacts, or the processes by which they were derived.

\subsubsection{Constructivist approach}

Constructivist models focus on those forms of learning that occur in the learner's guided exploration of and experimentation with the world, typically in classrooms or online environments. Constructivist models are likely to measure success as quality of construction, with learners experimenting with their environment, and being capable of using tools that are appropriate for their given age.

Analytics Implications: Learning analytics with a constructivist focus will focus on progress, particularly through tracking and judging the modifications made to a set of materials, resources, or tools selected and arranged by the educator. An example of analytics in this tradition would be tracking the evolution of digital artefacts within the Scratch visual programming environment and community (Maloney, Resnick, Rusk, Silverman, \& Eastmond, 2010).

\subsubsection{Subjectivist or affect-based approach}

Subjectivist perspectives can be characterized as de-emphasizing learning qua academia, with more attention to personal affect. While individual affect is a concern for educationalists, it is rarely if ever the overarching concern in the consideration of learning. One context in which affect is important is learning in complex socio-technical challenges: while there are certainly better and worse answers, there is too much information and no known best solution. Information seeking in such contexts can draw on subjectivist approaches that measure whether the user is "satisfied" with the information they have found. Another context in which self-reporting is an important proxy for learning is research into dispositions (Deakin Crick, Broadfoot, \& Claxton, 2004) and "mindsets" (Dweck, 2006) - learner willingness to engage with opportunities that will challenge them, or stretch other transferable competencies such as questioning or collaborating.

Analytics Implications: In tandem with other approaches, learning analytics based on subjectivist approaches are likely to provide motivation assessments for understanding why someone is (or is not) engaging in particular actions. Such analytics may focus on self-reporting through survey tools (Buckingham Shum \& Deakin Crick, 2012) or affect-based semantic mark-up such as blog tagging (Ferguson, Buckingham Shum \& Deakin Crick, 2011), alongside automated approaches such as textual sentiment analysis.

\subsubsection{Apprenticeship approach}

Apprenticeship approaches are sometimes used in learning analytics with an interest in whether the learner has become part of a community of practice or enquiry. In this view, success is about "being part of" a given group; it is bound up in notions of communities of practice - that "to know $x$ " is to act towards $\mathrm{x}$ in some way defined by (or reflected in) the behaviours of some community or other.

Analytics Implications: Analytics based on apprenticeship approaches are likely to focus on classifying 
expert and novice users, and the shift from novice to expert. Such analysis may explore behavioural markers that mirror those made by "experts," but may not explore the reasons or meanings implicated in such moves. Epistemic Network Analysis of user data from gaming environments is designed to quantify the degree to which learners demonstrate behaviours valued in a professional community (Shaffer et al., 2009). The creation of social capital might be considered another proxy for community membership, overlapping with the next category.

\subsubsection{Connectivist approach}

Connectivism claims to highlight a perspective on epistemology that translates into a learning analytics framework. Within this view, learning is about understanding how to connect ideas appropriately, and where to find such information. The suggestion is that in the case of the connectivist knower "the act of knowing is offloaded onto the network itself" (Siemens, 2006, p. 33). Within this perspective then, success is about building connections between ideas.

Analytics Implications: Connectivist approaches use network analysis to explore the "connectedness" of a learner's knowledge - in terms of both concepts, and social connections. Analytics would look at how networks' size, quality, and changes over time can serve as proxies for effective learning (Dawson, 2010; Haythornthwaite \& de Laat, 2010).

\subsubsection{Pragmatic, socio-cultural approach}

Pragmatic approaches (building on, for example, Dewey, 1998) hold that learning occurs in the development and negotiation of a mutually shared perspective between learners. Pragmatists suggest that, as human knowers, our conception of some given thing is bound up in our understanding of its practical application - and that is all. When we attempt to understand truth beyond such a conceptualization of practical activity, we are likely to fail. Thus, success is in use - the measure of success is how useful the information is for the purposes it is employed; it is socio-culturally embedded and mediated, and may be in flux as activities are defined and redefined.

Analytics Implications: Pragmatic approaches have traditionally focused less on assessing the products of learning (except where they are being used for something), and more on the process. Analytics tools in socio-cultural approaches encourage learners to reflect on their own activity, in an attempt to understand how they can develop their skills in information processing, in their own particular contexts. Analytics within this approach might attend particularly to quality of discourse for learning, for creating a mutuality of perspectives (Edwards \& Mercer, 1987) including in collaborative information seeking tasks (Foster, 2009; Hertzum, 2008; Lazonder, 2005). Our previous work is in this tradition, drawing on socio-cultural discourse analysis (Mercer \& Littleton, 2007), and emerging conceptions of the pragmatic web (Buckingham Shum, 2006). This research foregrounds how students interact with information, make sense of it in their context and co-construct meaning in shared contexts. These are on-going processes that highlight the question of how learning analytics fits into the context of $A f L$ and pedagogy.

Having summarized the sorts of relationships we might see between pedagogical approaches and learning analytics, let us turn to epistemology.

\subsection{Epistemology and Analytics}

The stance we take with regard to the relationship between epistemology, assessment, and learning analytics relates to the issue of whether we place analytics in the role of diagnosis or a kind of biofeedback. Is learning analytics (and assessment) serving as the end-point of, or a component of 
pedagogy? As a diagnostic, we seek to accredit learning through defining behavioural proxies taken as evidence of knowledge and competencies. As biofeedback, learning analytics is used to support learners in their own self-regulated learning activities, giving them feedback on changes they make and their impact on learning outcomes, but without, generally, making strong evaluative judgments regarding such changes. The former is thus more closely aligned with assessment of learning - often instantiated in high stakes summative assessment - while the latter is closer to assessment for learning - in which assessment is a continuous process through which formative feedback may be given to further develop student learning (see, for example, Black \& Wiliam, 2001; Gardner, 2011). If evidencing process-centric competencies is defined as part of the summative assessment criteria, then the two categories converge. For example, the process competencies of evidencing sound argumentation in discourse, higher resilience when stretched with new challenges, or the creation of social capital within a community of practice, might conceivably be assessed summatively through analytics.

The relationships highlighted in sections 4.1.1 to 4.1.6 serve as general pointers to the sorts of relationships we might see between pedagogy and learning analytics. There we also highlight views on learning, alongside notions of how success may be defined within these approaches; that is, when these systems might accredit knowledge to the student. Fundamentally, accreditation implicates epistemological stances regarding when knowledge may be claimed (or not). The preceding analysis suggests roles for learning analytics in accrediting mastery in three senses:

1. Mastering curriculum content: This is the dominant focus of analytics approaches at present, seeking behavioural markers using e-assessment technologies of varying sophistication, in order to generate summaries at varying granularities, for both individuals and cohorts. (See transactional and some constructivist approaches.)

2. Evidencing membership and processes: This approach to learning analytics looks for behavioural proxies that indicate a student is part of a particular subgroup; positive feedback is given towards moving students into "successful" subgroups, but little attention is paid to the qualities of those groups except instrumentally. (See affect-based, apprenticeship, and possibly connectivist approaches.)

3. Success is use: This approach looks for students developing personal and collective representations of curriculum content and engagement in sensemaking about not only this material, but also their own analytics. One characterization of this family of approaches has been as Social Learning Analytics (Buckingham Shum \& Ferguson, 2012). (See connectivist and pragmatist approaches.)

These three broad conceptualizations of learning analytics relate to the issue of whether or not we are deemed to consume, discover, or create knowledge - is it "out there" for us to take, do we need to investigate to find it, or is it emergent from the contexts in which that knowledge is applied and reified in activity? This is not a claim about learning or pedagogy, but a related claim about the status of knowledge and its assessment. We discuss this further in section 6.4 with reference to a particular example.

\subsubsection{Pragmatism and socio-cultural definitions of "context"}

The nuance of claims surrounding epistemology and assessment is important. In the introduction we referred to research arguing that conventional exams are designed to maximize the reliability of results, at the cost of straitjacketing what can be defined as learning (poor internal or construct validity) and thus what constitutes evidence of learning (poor external validity). Moreover, if we are to argue that individual tokens of knowledge cannot be identified (and "owned"), then we should accept that "the 
content of a specific item of knowledge depends in part on how it is related to other knowledge" (Davis, 2006). Thus, socio-cultural setting, interaction, and the purposes for which any artefact or knowledge in the broadest sense - is being used are all of fundamental importance in understanding how people make meaning and learn. Contextual sensitivity is thus a key facet of pragmatist approaches.

Pragmatic approaches, broadly, are likely to focus on the dynamic nature of information needs, and the discourse and other artefacts that mediate our relationship with information in the world. It is not a postmodern approach, in the sense that postmodern approaches take either a relativist approach (there is no fixed truth) or a normative one (the dominant theme is correct at that time) to knowledge, but rather one that focuses on use, and meaning, over accreditation of facts to things in the world.

Given the salience of context in this approach, it deserves further explication. As with learning analytics generally, context may be taken as very mechanistic; for example, the claim that a person in place/course/role/ability band " $x$ " should see resource " $y$," or other approaches that would include time, topic, or social-group resource discovery. No doubt, some of these features will prove useful, and indeed the use of semantic web technology in social learning analytics (Ferguson \& Buckingham Shum, 2012) may be particularly interesting. However, in addition to computational, context is often defined in terms of temporal, linguistic, aptitude, and geo-spatial metadata. In discourse, however, we draw attention to the following:

1. We emphasize the discourse in which, and through which, context is constituted (Edwards \& Furlong, 1978; Potter \& Edwards, 2003). That is, we take the discourse to have a multifaceted role in constituting, and helping learners make sense of, the context.

2. Discourse is fundamentally associated with the sense-making that occurs in respect of any particular task being undertaken; the use being targeted is fundamental to context. Stark examples highlight this importance; for example, when we ask students to critique versus summarize a paper, we expect rather different outcomes. Assessment regimes that make this explicit may facilitate the design of analytics that capture the context of "doing $x$ for purpose $y$. "

3. Assessment regimes, and the broad range of tools, technological and otherwise used by learners, also act as mediating artefacts impacting how people perceive their task and its solution, which all shape the context of use.

A conception of learning analytics that recognizes the importance of context is central to epistemic beliefs:

A sophisticated epistemology entails context-sensitive judgements. Thus, they point out that it is not very sophisticated to view the idea that the earth is round rather than flat as "tentative" whereas theories of dinosaur extinction do require a more tentative stance. (Barzilai \& Zohar, 2012, p. 42)

Similarly, building spurious connections between ideas in an attempt to evidence a "complex" view of knowledge is less sophisticated than demonstrating the need for moderation, and so on. Context is thus key to understanding epistemic beliefs, the analysis of which seems highly suited to the biofeedback approach to formative assessment analytics, introduced earlier.

The next section further expands this claim in the context of psychological assessment of epistemic beliefs, firstly in "mainstream" psychological approaches, and then that of the discursive approach, 
which similarly holds context and discourse to be fundamental to understanding thinking. Section 6 then returns to learning analytics, drawing out the relationship between analytics, and the measurement of epistemic beliefs in our illustrative example for socio-cultural, pragmatic analytics.

\section{MEASURING EPISTEMIC BELIEFS}

The complexity of epistemic cognition suggests a particular perspective on how we are to understand these beliefs. No approach "mirrors" reality with a true, immutable, incontrovertible perspective on a learner's epistemic cognition. This concern is a dual one. Firstly, it is a methodological concern regarding our access to the world, our ability to "get at" what is out there. Secondly, it is a conceptual and psychological concern, regarding the nature of epistemic cognition and whether it itself is stable developmentally, and across domains - or shaped in some way by resources or beliefs. These two concerns are reflected in the epistemic beliefs literature. Firstly, cognitive developmental models (King \& Kitchener, 2004; Kuhn \& Weinstock, 2002) suggest that individuals progress through a sequence of increasingly sophisticated epistemic beliefs, while multidimensional perspectives (Hofer, 2001; Schommer, 1990) suggest that epistemic beliefs can be separated into dimensions, within which levels of sophistication can be identified (Greene, Muis, \& Pieschl, 2010, p. 248). However, both of these assume a fixed, uni-directional developmental trajectory, where beliefs are seen as global across (and within) domains. The resources view, in contrast, emphasizes the interaction of believer, with resources, highlighting that at various points in any task a cognizer may invoke differing resources (Hammer \& Elby, 2003).

Secondly, methodologically the developmental models have tended towards interviews and laboratory tasks, while multidimensional models have emphasized paper and pencil self-report measures (DeBacker, Crowson, Beesley, Thoma, \& Hestevold, 2008). Both of these approaches reflect the fixed perspective on beliefs from which theory they stem. Importantly, although three major survey instruments have been developed and deployed, - including in search engine tasks (Lin \& Tsai, 2008; Schommer, 1990) - they are heavily criticized for their psychometric properties (DeBacker et al., 2008). Furthermore, while some studies have used interviews (Barzilai \& Zohar, 2012; Mason et al., 2009), think-aloud protocols (Barzilai \& Zohar, 2012; Ferguson, Bråten, \& Strøms $\varnothing, 2012$ ), or systematic observations (Scherr \& Hammer, 2009) such methods may be limited in their insights, particularly where self-report data is to be used and interpreted by researchers. Importantly, they are also not appropriate for the study of online, collaborative, or geographically and temporally spread activities - in particular, online information seeking, or information processing more broadly. These approaches reflect the epistemology of current assessment regimes, as indicated in Section 2, and seem to implicate the view of "fixed" psychological constructs - whether intelligence or epistemic beliefs, as further discussed throughout Section 3.

Building on sections 4.1.1 to 4.1.5, we can identify a number of analytic tools and their relationships to particular forms of data. Some forms of analytics rely on a belief that particular methods (self-report in particular) are: a) true reflections of reality, b) whole reflections of reality (i.e., they cover all the relevant ground), and c) probe "real" constructs. However, while self-report measures may be useful particularly as discussion prompts with students, they are not necessarily the most useful approach for many purposes. In both assessment and psychological testing, they suffer from issues of validity (Section 2). Thus, other learning analytics tools may prove more useful.

That is not to write off such tools, which may be particularly useful in exploring population differences and providing basic metrics to distinguish between people (candidates for a job, for example). Rather, it 
is to note that they do not align well with formative assessment (although some may be used for such purposes); they have a tendency to "teach to the test" - or in the case of psychometrics, to rely on tightly culturally bound constructs; they are often used to make claims about states of the world as "products" rather than an exploration of processes and wider contexts.

In contrast, while those adopting a resources view of epistemic beliefs may also utilize such methods in particular those involving think aloud and interview data - they also accord well with Österholm's discursive stance, which suggests that we should not see beliefs and communication as "two separate 'objects' that can affect each other, but as more integrated aspects of cognition and/or behaviour" (Österholm, 2010, p. 242). The resources view describes "the activity, the discourse, as the site where epistemological beliefs come to existence, through explicit or implicit references to prior experiences (epistemological resources)" (Österholm, 2009, p. 262). Österholm's argument is that the resources perspective can be combined with Hammer and Elby's (2003) resources model. In this model, epistemic beliefs are not viewed as fixed or developing cognitive models ranging over one or more domains, but rather are seen as dependent upon the resources available to the cognizer at any time. This view of epistemic beliefs as "theory-in-action" - in which context, domain, culture, and task conditions interact - accords well with the idea that context is fundamental to understanding meaning.

\subsection{Trace Data for Epistemic Beliefs}

While Österholm is primarily interested in spoken interactions, learning analytics may extend this interest into the exploration of users' interactions with artefacts. A tool for such analysis may come through the use of trace data, which is more or less implicitly created by the student. For example, Stadtler and Bromme (2007) analyzed the ways participants found, extracted, and moved information, which could be used to explore information about their beliefs (e.g., visiting few websites indicates trust in those sites visited; Greene et al., 2010). Importantly in this study, users were either given evaluation prompts regarding multiple documents in the medical domain or not; those who received such prompts subsequently recalled more facts and were better able to evaluate sources. If systems of prompts promote laziness, we should be concerned. Where they improve outcomes, however, analytics should explore the best ways to implement them effectively and sustainably to support high quality pedagogy and AfL.

Furthermore, Greene et al. (2010) point out that many behaviours that would ordinarily be difficult to observe can be explicitly elicited in the context of Computer Based Learning Environments (CBLEs), for example:

...participants who report belief in objective truth and omniscient authority may selfregulate quite differently than participants with a desire to evaluate multiple forms of justification. Likewise, participants who believe in the inherent subjectivity of all knowledge may, on average, select more representations than those who look for an objective truth. (Greene et al., 2010, p. 254)

The claim is thus that epistemic beliefs will be brought to bear on knowledge tasks in ways that can be meaningfully captured, in particular using the digital trace data left as a "by-product" of engaging in tasks (such as issuing searches, browsing websites, or messaging peers), or through the intentional creation of digital artefacts whose evolution can be traced (e.g., documents, bookmark collections, concept maps). 
Trace-based learning analytics provides a means to tackle the static, decontextualized view of epistemic beliefs instantiated by questionnaire methods, offering a more authentic perspective on epistemic action than experimental contexts. However, the limit on what can be inferred about the mind of a user solely from low-level system traces is a well known problem in human-computer interaction. While trace data is unobtrusive, it necessarily gives an incomplete picture. In particular, people may have reasons for some behaviours that cannot be probed using such data, ranging from epistemic (as discussed above, for example with regard to the "flat earth" issue), to practical (ICT failures), to pragmatic (the demands of the task place a short time restriction on the activity), and so on. In summary, even though analytics regarding epistemic beliefs may be - at best - a dirty lens onto those beliefs, when analytics are considered in action as a tool for sense-making, they may provide an insightful tool for learners to dissect their own metacognitive and self-regulatory behaviours, as well as for educators and researchers to study them.

Trace data thus provides one means by which epistemic beliefs could be examined. However, trace could refer to many things, and as discussed in sections 4.1 .1 to 4.1.5, the data collected may not represent an appropriate teaching epistemology, nor capture adequately student epistemologies (see section 2). The next section will discuss some learning analytics that may address this issue. An interesting notion then, is attempting to delve further into the sense-making significance behind particular semantic moves in a given environment. Thus, Greene et al. (2010) (see Section 5.1) described one method of trace analysis for epistemic beliefs built on information moves. Other examples of such trace capture could also be structured to gather student data in particular ways - some of which may be quite naturalistic (capturing search queries, or Facebook posts to explore "problems" encountered, or interactions made; De Liddo, Buckingham Shum, Quinto, Bachler, \& Cannavacciuolo, 2011), and others of which might push students into information structuring activity in which they would not otherwise engage, such as argument mapping.

However, in encouraging such structuring by learners, and claiming to capture information about what they are doing, some may argue that we are simply reifying the constructs we have set out to explore. That is, if we are interested in epistemic beliefs, and set up a system to push students to make epistemic beliefs explicit, it does not matter whether those students have underlying epistemic beliefs because the system forces them into making some (it makes them reify). While for psychologists who wish to uncover underlying beliefs using the kind of psychometrics described above this is problematic, we do not see this as a concern for our project, because in our discursive, socio-cultural, pragmatic approach the interest is in beliefs as "theory-in-action." In this view, the claim is not that the measurement of beliefs is not possible, but rather that when we take measurements, the discursive context is fundamental to the practices being observed, and the ways that the beliefs are instantiated in action. Thus, learning analytics provides a means to tackle the static, decontextualized view of epistemic beliefs instantiated by questionnaire methods, offering a more authentic perspective on epistemic action than experimental contexts.

\section{EXAMPLE: DISCOURSE-CENTRIC ANALYTICS FOR EPISTEMIC BELIEFS}

We have reviewed the ways in which the educational triad bounded by epistemology, assessment, and pedagogy defines critical aspects of the "middle space" between learning and analytics, which can lead to very different kinds of analytics. We now present a more developed example, to illustrate how the preceding discussion can translate into tangible design.

Within a pragmatic socio-cultural perspective on the triad, use of knowledge, and an understanding of 
its rich culturally embedded connectedness is fundamental. We have emphasized the role of context at various points throughout this piece, indicating in particular the need to understand discourse as created in, and a creator of, context. The perspective is thus fundamentally social in nature, taking knowledge to be discursive in nature, with learners benefiting in particular from timely formative feedback in which language is used to construct knowledge.

Standardized assessments, just as psychometric tests, are good at population-level analytics. However, they are problematic at individual level analysis, at understanding change, and at understanding individual traits and capabilities. The perspective we have outlined in this paper suggests analytics may play an important role in assessment for learning, providing formative, individualized, feedback to learners and their teachers.

In the following example, we exemplify such an approach; however, while we hope the example given is illustrative, it is not intended to be proscriptive nor indeed do we claim it is without faults; rather, we seek to illustrate how the stance we have taken here has been "brought out" in the analytics - how we have brought the learning and the analytics together, using the triad to bound that middle space.

This example offers an illustration of how an analytic device might be used to offer formative feedback. In this case, our focus is not explicitly on the content level knowledge claims we can make regarding student learning, but rather on how students develop their understanding. The example offers a means to explore supporting student learning through formative feedback, and social learning of a discursive nature. Of course, further consideration should be given to the wider context of the activity and discourse we would wish to provoke.

Our example comes from work at the Open University, based around the Cohere social annotation and knowledge mapping tool (Buckingham Shum, 2008) and subsequent work on its potential for sociocultural discourse-centric learning analytics (De Liddo et al., 2011). Cohere is a web application for mapping ideas, concepts, and arguments that can be annotated directly onto source websites. Users enter ideas - nodes with meaningful classifications - and are then invited to "make the connection" with meaningfully labelled edges, to create a conceptual graph. Both ideas and connections may also be tagged, to add a further level of semantic data. Cohere is designed as a tool to enable users to build their own structures, but also to share these, and integrate the nodes and connections of other users, thus building up communities of enquiry around particular disciplinary topics. This deliberate design decision not to impose an ontology onto users makes it explicitly pragmatic, and discursive in nature (Buckingham Shum, 2006). In the context of learning sciences and CSCL research, Cohere is a Web 3.0 (social and semantic web) era application exemplifying the knowledge-building paradigm that has inspired earlier reflective, knowledge structuring software tools (Novak, 1998; Scardamalia and Bereiter, 1993; Suthers, Weiner, Connelly, \& Paolucci, 1995).

Thus, Cohere renders proxies of learner understanding in the form of a semantic network of textual nodes that may also link to multimedia resources. Three recent technical advances are also of note: a version called the Evidence Hub now feeds analytics back to end users as well as to system administrators, and enables the embedding of multimedia within nodes (De Liddo and Buckingham Shum, 2013), while the textual content of nodes can now be analyzed for significant patterns using a rhetorical parser (Simsek, Buckingham Shum, Sándor, De Liddo \& Ferguson, 2013). Together, these open the possibility for analytics to offer insight into epistemic beliefs, as summarized in Table 2, which returns to the broad epistemic "dimensions" introduced earlier (Table 1), and gives examples of proxies within socio-semantic trace data, plus guidance indicative of the sorts of challenges that might be posed 
to students to extend their epistemic cognition and probe their learning processes. ${ }^{4}$

We emphasize again that is not just the representational affordances of the analytics tool, but its use that will ultimately determine its impact. The representational scheme of semantically typed nodes and links clearly requires learner reflection and intentional artefact construction not normally demanded by conventional social platforms, and is thus theoretically tied to a socio-culturally inspired triad. However, both the constructs and the trace should be seen in their situated context: prior research into argumentation demonstrates that many elements in the cognitive and socio-cultural environment influence the usage patterns and impact of such tools (Scheuer, Loll, \& McLaren, 2010). Key variables include user familiarity with the tool, their willingness to challenge each other in public, and the task set by teachers (this is a reiteration of the claims made at the end of Section 2). Thus, these should be dynamic tools, and empirical work will be needed to explore the relationship between feedback given, representations allowed, student responses to feedback, and the impact of this on learning.

Table 2. Trace Patterns and Guidance for Epistemic Beliefs

\begin{tabular}{|c|c|c|}
\hline $\begin{array}{l}\text { Dimensions of } \\
\text { Epistemic Belief }\end{array}$ & $\begin{array}{c}\text { Candidate Socio/Semantic Trace } \\
\text { Patterns }\end{array}$ & $\begin{array}{l}\text { Guidance/Challenge } \\
\text { to the Learner }\end{array}$ \\
\hline $\begin{array}{l}\text { Certainty } \\
\text { The degree to which } \\
\text { knowledge is } \\
\text { conceived as stable } \\
\text { or changing, ranging } \\
\text { from absolute to } \\
\text { tentative and } \\
\text { evolving knowledge }\end{array}$ & $\begin{array}{l}\text { Frequency and density of positive and } \\
\text { negative polarity links (e.g., supports; } \\
\text { builds on; is consistent with, versus } \\
\text { challenges; refutes; is inconsistent with). } \\
\text { Presence of stability markers - (e.g., } \\
\text { current sources; bibliographic references; } \\
\text { geographical spread). } \\
\text { Frequency and density of meta-discourse } \\
\text { markers in the text of nodes, which } \\
\text { moderate assertions in scholarly ways } \\
\text { (e.g., in contrast to; remains an } \\
\text { unresolved issue) }\end{array}$ & $\begin{array}{l}\text { Are there no downsides to this } \\
\text { claim? } \\
\text { Can you find a counterexample? } \\
\text { Is this idea consistent across } \\
\text { time/place? Have you looked at } \\
\text { XY map? }\end{array}$ \\
\hline
\end{tabular}

${ }^{4}$ Following previous work (De Liddo, Buckingham Shum, Quinto, Bachler, \& Cannavacciuolo, 2011) the basic analytic statistic is constructed as a percentage representation of the target type, over the total types created by the user. For example, the number of "opinion" nodes created, as a percentage of the total number of nodes created by that user. 
(2014). Epistemology, Assessment, Pedagogy: Where Learning Meets Analytics in the Middle Space. Journal of Learning Analytics, 1(2), 23-47.

\begin{tabular}{|c|c|c|}
\hline $\begin{array}{l}\text { Simplicity } \\
\text { The degree to which } \\
\text { knowledge is } \\
\text { conceived as } \\
\text { compartmentalized } \\
\text { or interrelated, } \\
\text { ranging from } \\
\text { knowledge as made } \\
\text { up of discrete and } \\
\text { simple facts to } \\
\text { knowledge as } \\
\text { complex and } \\
\text { comprising } \\
\text { interrelated concepts }\end{array}$ & $\begin{array}{l}\text { Standard network analytics describing } \\
\text { the topography of the structure } \\
\text { Semantic analysis of node and link types } \\
\text { describing the variety of types used by a } \\
\text { learner, the balance in link polarity } \\
\text { (positive/neutral/negative), and the } \\
\text { balance of propositional (causes; refutes; } \\
\text { solves) versus analogical thinking (is a } \\
\text { metaphor of; is analogous to). } \\
\text { Semantic analysis of tags on nodes and } \\
\text { links } \\
\text { Encapsulation of node clusters or sub- } \\
\text { networks within a broader category } \\
\text { expressing a higher order construct } \\
\text { The use of different argumentation } \\
\text { schemes, which reflect different sources } \\
\text { of authority (argument from expertise; } \\
\text { argument by analogy; argument from } \\
\text { precedent) } \\
\text { In collaborative maps, the social network } \\
\text { view showing who is connected to whom, } \\
\text { but what kinds of links }\end{array}$ & $\begin{array}{l}\text { Have you considered how } \mathrm{X} \text { and } \mathrm{Y} \\
\text { might be connected? } \\
\text { Why is this node so } \\
\text { (dis)connected? } \\
\text { Would you not expect this } \\
\text { network to be better connected? } \\
\text { Does it make sense that this } \\
\text { paper is in the hub? } \\
\text { Does this analogy hold in all } \\
\text { cases? (And many other critical } \\
\text { questions used to probe } \\
\text { arguments: Buckingham Shum } \\
\text { and Okada, 2008) } \\
\text { Is it significant that these two } \\
\text { analysts are not connecting their } \\
\text { ideas to each other? }\end{array}$ \\
\hline $\begin{array}{c}\text { Source } \\
\text { The relationship } \\
\text { between knower and } \\
\text { known, ranging from } \\
\text { the belief that } \\
\text { knowledge resides } \\
\text { outside the self and is } \\
\text { transmitted, to the } \\
\text { belief that it is } \\
\text { constructed by the } \\
\text { self }\end{array}$ & $\begin{array}{l}\text { Presence within the text of nodes of "I } \\
\text { think" or other restatements of fact } \\
\text { Challenges to claims through negative } \\
\text { link types and meta-discourse markers in } \\
\text { node text } \\
\text { Few additional nodes made other than } \\
\text { those created as quotations. }\end{array}$ & $\begin{array}{l}\text { What do you think of these } \\
\text { ideas? } \\
\text { Doesn't your perspective raise } \\
\text { important questions for this } \\
\text { claim? } \\
\text { How does the evidence relate to } \\
\text { your view? }\end{array}$ \\
\hline
\end{tabular}


(2014). Epistemology, Assessment, Pedagogy: Where Learning Meets Analytics in the Middle Space. Journal of Learning Analytics, 1(2), 23-47.

\begin{tabular}{|c|c|c|}
\hline $\begin{array}{c}\text { Justification } \\
\text { What makes a } \\
\text { sufficient knowledge } \\
\text { claim, ranging from } \\
\text { the belief in } \\
\text { observation or } \\
\text { authority as sources, } \\
\text { to the belief in the } \\
\text { use of rules of inquiry } \\
\text { and evaluation of } \\
\text { expertise }\end{array}$ & $\begin{array}{l}\text { Judgements of relevance, and supporting } \\
\text { or explanatory notes ("this } \\
\text { evidences/explains x"); ties to method } \\
\text { "ideas" } \\
\text { Use of well known Argumentation } \\
\text { Schemes, especially evidence and } \\
\text { arguments grounded in the attribution of } \\
\text { authority to people ("experts") or } \\
\text { publications based on their status } \\
\text { ("valuing peer review") } \\
\text { Rhetorical constructions in node text that } \\
\text { show a critical use of sources }\end{array}$ & $\begin{array}{l}\text { What evidence do we have for } \\
\text { this idea? } \\
\text { Is it "good" evidence? Why/why } \\
\text { not? } \\
\text { You seem to quote/cite sources } \\
\text { without much commentary of } \\
\text { your own - bring in your voice } \\
\text { more. }\end{array}$ \\
\hline
\end{tabular}

This example thus provides space to consider the role of the epistemology, assessment, and pedagogy in bounding learning analytics. In this case, assessment - or "measurement," analytics, data gathering, etc. - is used to support learning, and the exploration of that learning. The technological support provides space for discursive, socio-culturally motivated pedagogy. Finally, the aim of the analytic device is not to make claims about a learner's knowledge states at any particular moment, nor to provide psychometric assessment of groups of students, but rather to provide a discussion object, and to probe student sense-making processes, and understanding - their justifications for claims, a classic definition of knowledge - and thus an epistemological component of our analysis.

\subsection{Many Lenses on Epistemic Beliefs}

Table 2 thus proposes one set of traces from which meaningful data could be captured. This is not, however, to dismiss other approaches discussed in Section 4.1. The epistemological approach discussed throughout this work is instead intended to indicate that what drives our learning analytics - and assessment - is not what they are, but rather, what we do with them. Our suggestion is that many of these approaches to learning analytics - these dirty lenses on the world - provide insights into different levels of learning, and tools for meaning-making. For example, with this richer than normal data model in place, it is very simple, computationally, to feed back the number of ideas and connection types used, but this may provoke meaningful dialogue regarding what these other types might be used for, or why they have not thus far been used. Similarly, constructive discourse might occur around the reasons why one student's map is more connected (but perhaps not appropriately so) than another's.

There is a strong relationship between analytics, assessment, pedagogy, and epistemology (Figure 1); learning analytics should be mindful of this triad, which socio-cultural analytics bridges well. Our approach should be seen as one of "many lenses" for many contexts, used in combination with the more conventional forms of learning analytics currently dominating. In this last section before concluding, we outline how the approaches discussed in Section 4.1 relate to epistemic beliefs, and some strengths and limitations of these approaches:

Learning analytics based on Transactional approaches. Approaches that emphasize fixed, "correct" knowledge, over how those facts are used to display understanding, are likely to encourage lower epistemic cognition, and implicate more "realist" epistemologies that see knowledge as a reflection of "things" in the world. 
Learning analytics based on Constructivist approaches. Similarly, there may be an overemphasis on a limited range of knowledge in constructivist approaches that emphasize development qua progression, but without considering the socio-cultural context in which that progression occurs, nor the wide range of uses for which it may be deployed. This may be particularly true in constrained systems that guide students through pre-set tasks and levels of attainment to meet, pre-specified software, and so on, as compared to those exploring knowledge co-constructed in discourse Understanding the ways that students build knowledge claims - understanding connections, justifications, change over time, and nuance - is fundamental to understanding their epistemic beliefs. Knowing that a student is at stage $x$ of $y$ in development may be less significant.

Learning analytics based on Apprenticeship approaches. In a similar vein, apprenticeship approaches can offer useful insight into group membership and the development of a student's thinking. However, the approach described in this paper suggests the best way to think about such approaches is with respect to the functional role that such community membership plays in a student's epistemic action, and their normative standards.

Learning analytics based on Subjectivist approaches. Learning analytics based on "affect" could be useful to the analysis of epistemic beliefs, with their analysis of "satisfaction" with information, e.g., enquiry-based learning (Ferguson et al., 2011); self-efficacy in IR information seeking (Tsai \& Tsai, 2003); satisfaction with search results (Huffman \& Hochster, 2007). As such, affective analytics might be used to explore whether learners are prematurely satisfied with findings that a peer or educator deems to be inadequate, or if they have an appropriate sense of disquiet or frustration with a flawed argument or methodology.

\section{CONCLUSION}

This paper opened with the argument that the triad of epistemology, assessment, and pedagogy are fundamentally entwined. Furthermore, we suggested that a focus on high-stakes assessment - which learning analytics may well be used to perpetuate - is detrimental to the wider enterprise of education, prioritizing the reliability of tightly defined assessments over continuing, formative assessment for learning, and authentically situated learning that is harder to fit into formal examination contexts. This is problematic as it limits the ways we can challenge students in assessments, and fails to reflect their encounters with knowledge claims in the world beyond the classroom walls. Learning Analytics should be mindful of the epistemological, assessment, and pedagogic implications of their application, and should be cautious of falling into technological determinism.

We have highlighted that transactional approaches may emphasize the use of facts; constructivist the broad (and contextual) application of skills; subjectivist the self-efficacy and motivators of students; apprenticeship the dynamic practical-based learning that may occur through high-level membership of communities of practice; connectivism the ability of students to build up, link, and curate their knowledge "networks." A socio-cultural, pragmatic approach may offer an additional toolset, alongside a theoretical frame through which to use other learning analytics lenses. All are partial (in bias, and hence in their coverage of all that might be measured), but may be used in complementary ways.

Analytics from user traces provide a means to track and record previously ephemeral process data, which could benefit assessment for learning in significant new ways. Pragmatist approaches, which emphasize use and meaning-making over the accrediting of true statements, may have an important role here. The grasp of curriculum facts and methods remains critical but the emphasis shifts to their 
effective, contextualized use, in argument structures, in discussion, in problem-solving. A focus on the socio-cultural learning system draws attention to how analytics take into account the centrality of discourse for sense-making, and in constituting "context."

We have gone beyond "our learning analytics are our pedagogy" (Buckingham Shum, 2012), arguing in more detail that analytics also embody related epistemological assumptions, thus perpetuating related assessment regimes. Since learning analytics unavoidably embody these triadic assumptions, there is the risk of perpetuating the limitations of current educational practices, especially those associated with high stakes testing.

In conclusion, the stakes are high. As du Gay and Pryke (2002, pp. 12-13) observe, "accounting tools ... do not simply aid the measurement of economic activity, they shape the reality they measure." As educational institutions adopt platforms and applications that make it increasingly easy to capture particular kinds of data, conduct certain analyses, and foreground particular patterns for human attention, they reinforce their location within the triad. Educators, possibly held to account with analytics-based performance indicators, may well come to design learning in a way that will enable them to evidence impact with these new tools. Students, aware that their behaviour is being tracked, may similarly seek to "evidence" their progress, and game the more simplistic measures. Technology alone does not determine practice; moreover, as with any tool, it is not only the design of the tool, but the way in which it is wielded in context, that defines its value.

\section{ACKNOWLEDGEMENTS}

We are grateful to Cindy Kerawalla and three anonymous reviewers for helpful comments on an earlier version of this paper presented at the LAK13 conference, and to Dan Suthers and the LAK13 attendees who offered helpful feedback, which was used in developing this extended version.

\section{REFERENCES}

Barzilai, S., \& Zohar, A. (2012). Epistemic thinking in action: Evaluating and integrating online sources. Cognition and Instruction, 30(1), 39-85. doi:10.1080/07370008.2011.636495

Black, P., \& Wiliam, D. (2001). Inside the black box. BERA. Retrieved from http://www.collegenet.co.uk/admin/download/inside\%20the\%20black\%20box_23_doc.pdf

Black, P., \& Wiliam, D. (2009). Developing the theory of formative assessment. Educational Assessment, Evaluation and Accountability, 21(1), 5-31.

Bromme, R., Pieschl, S., \& Stahl, E. (2009). Epistemological beliefs are standards for adaptive learning: A functional theory about epistemological beliefs and metacognition. Metacognition and Learning, 5(1), 7-26. doi:10.1007/s11409-009-9053-5

Buckingham Shum, S. (2006). Sensemaking on the pragmatic web: A hypermedia discourse perspective. $1^{\text {st }}$ International Conference on the Pragmatic Web. 21-22 Sept 2006, Stuttgart. Open Access Eprint: http://oro.open.ac.uk/6442

Buckingham Shum, S. (2008). Cohere: Towards web 2.0 argumentation. Proceedings of the 2nd International Conference on Computational Models of Argument. 28-30 May 2008, Toulouse, France. IOS Press, 97-108. http://oro.open.ac.uk/10421 
(2014). Epistemology, Assessment, Pedagogy: Where Learning Meets Analytics in the Middle Space. Journal of Learning Analytics, 1(2), $23-47$.

Buckingham Shum, S. (2012). Our learning analytics are our pedagogy. Keynote Address, presented at the Expanding Horizons 2012 Conference, Macquarie University. Retrieved from http://www.slideshare.net/sbs/our-learning-analytics-are-our-pedagogy

Buckingham Shum, S., \& Deakin Crick, R. (2012). Learning dispositions and transferable competencies: Pedagogy, modelling and learning analytics. Proceedings of the 2nd International Conference on Learning Analytics \& Knowledge. 29 Apr-2 May, Vancouver, BC. New York: ACM, 92-101. Eprint: http://oro.open.ac.uk/32823

Buckingham Shum, S., \& Ferguson, R. (2012). Social learning analytics. Educational Technology \& Society, 15(3), 3-26.

Buckingham Shum, S., \& Okada, A. (2008). Knowledge cartography for controversies: The Iraq debate. In A. Okada, S. Buckingham Shum, \& T. Sherbone (Eds.), Knowledge cartography: Software tools and mapping techniques. London: Springer.

Crook, C., \& Lewthwaite, S. (2010). Technologies for formal and informal learning. In K. Littleton, C. Wood, \& J. K. Staarman (Eds.), International Handbook of Psychology in Education (pp. 435461). Bingley, UK: Emerald Group Publishing.

Cunnane, S. (2011, May 12). The Danish gambit: Online access, even during exams. Times Higher Education. Retrieved from http://www.timeshighereducation.co.uk/story.asp?sectioncode $=26 \&$ storycode $=416090 \& \mathrm{c}=1$

Davis, A. (1998). Understanding and holism. Journal of Philosophy of Education, 32(1), 41-55.

Davis, A. (1999). The Limits of Educational Assessment. Hoboken, NJ: Wiley-Blackwell.

Davis, A. (2005). Learning and the social nature of mental powers. Educational Philosophy and Theory, 37(5), 635-647. doi:10.1111/j.1469-5812.2005.00148.x

Davis, A. (2006). High stakes testing and the structure of the mind: A reply to Randall Curren. Journal of Philosophy of Education, 40(1), 1-16. doi:10.1111/j.1467-9752.2006.00492.x

Davis, A., \& Williams, K. (2002). Epistemology and curriculum. In N. Blake, P. Smeyers, \& R. Smith (Eds.), The Blackwell guide to the philosophy of education. Blackwell Reference Online.

Dawson, S. (2010). "Seeing" the learning community: An exploration of the development of a resource for monitoring online student networking. British Journal of Educational Technology, 41, 736752.

Deakin Crick, R., Broadfoot, P., \& Claxton, G. (2004). Developing an effective lifelong learning inventory: The ELLI project. Assessment in Education, 11, 248-272.

De Liddo, A., \& Buckingham Shum, S. (2013). The evidence hub: Harnessing the collective intelligence of communities to build evidence-based knowledge. Large Scale Ideation and Deliberation Workshop, 6th International Conference on Communities \& Technologies. 29 June 2013, Munich. Open Access Eprint: http://oro.open.ac.uk/38002

De Liddo, A., Buckingham Shum, S., Quinto, I., Bachler, M., \& Cannavacciuolo, L. (2011). Discoursecentric learning analytics. Proceedings of the 1st International Conference on Learning Analytics and Knowledge (pp. 23-33). New York: ACM. doi:10.1145/2090116.2090120

Dweck, C. (2006). Mindset: The new psychology of success: New York: Random House. 
(2014). Epistemology, Assessment, Pedagogy: Where Learning Meets Analytics in the Middle Space. Journal of Learning Analytics, 1(2), $23-47$.

DeBacker, T. K., Crowson, H. M., Beesley, A. D., Thoma, S. J., \& Hestevold, N. L. (2008). The challenge of measuring epistemic beliefs: An analysis of three self-report instruments. The Journal of Experimental Education, 76(3), 281-312. doi:10.3200/JEXE.76.3.281-314

Dede, C. (2008). A seismic shift in epistemology. EDUCAUSE Review, 43(3), 80-81.

Dewey, J. (1998). Experience and education. Kappa Delta Pi. Retrieved from http://ruby.fgcu.edu/courses/ndemers/colloquium/ExperiencEducationDewey.pdf

du Gay, P., \& Pryke, M. (2002). Cultural economy: Cultural analysis and commercial life. London: Sage.

Edwards, A. D., \& Furlong, V. J. (1978). The language of teaching: Meaning in classroom interaction. London: Heinemann. Retrieved from http://www.getcited.org/pub/102019252

Edwards, D., \& Mercer, N. (1987). Common knowledge: The development of understanding in the classroom. London: Routledge.

Ferguson, L. E., Bråten, I., \& Strøms $\varnothing$, H. I. (2012). Epistemic cognition when students read multiple documents containing conflicting scientific evidence: A think-aloud study. Learning and Instruction, 22(2), 103-120. doi:10.1016/j.learninstruc.2011.08.002

Ferguson, R., \& Buckingham Shum, S. (2012). Social learning analytics: Five approaches. Proceedings of the 2nd International Conference on Learning Analytics \& Knowledge, Vancouver, BC. New York: ACM Press. Retrieved from http://projects.kmi.open.ac.uk/hyperdiscourse/docs/learning analyticsK2012-RF-SBS.pdf

Ferguson, R., Buckingham Shum, S., \& Deakin Crick, R. (2011). EnquiryBlogger: Using widgets to support awareness and reflection in a PLE setting. 1st Workshop on Awareness and Reflection in Personal Learning Environments, Southampton, UK. Retrieved from http://oro.open.ac.uk/19576/1/Producing_Animations_to_educate_MSM.pdf

Foster, J. (2009). Understanding interaction in information seeking and use as a discourse: A dialogic approach. Journal of Documentation, 65(1), 83-105. doi:10.1108/00220410910926130

Gardner, J. (2011). Assessment and learning (2nd ed.). London: SAGE.

Greene, J. A., Muis, K. R., \& Pieschl, S. (2010). The role of epistemic beliefs in students' self-regulated learning with computer-based learning environments: Conceptual and methodological issues. Educational Psychologist, 45(4), 245-257. doi:10.1080/00461520.2010.515932

Hamilton, E., \& Feenberg, A. (2005). The technical codes of online education. Techné: Research in Philosophy and Technology, 9(1). Retrieved from http://scholar.lib.vt.edu/ejournals/SPT/v9n1/hamilton.html

Hammer, D., \& Elby, A. (2003). Tapping epistemological resources for learning physics. Journal of the Learning Sciences, 12(1), 53-90. doi:10.1207/S15327809JLS1201_3

Harlen, W. (2007). Assessment of learning. London: SAGE.

Hertzum, M. (2008). Collaborative information seeking: The combined activity of information seeking and collaborative grounding. Information Processing \& Management, 44(2), 957-962. doi:10.1016/j.ipm.2007.03.007

Haythornthwaite, C., and de Laat, M. (2010). Social networks and learning networks: Using social network perspectives to understand social learning. In L. Dirckinck-Holmfeld, V. Hodgson, C. Jones, M. de Laat, D. McConnell, \& T. Ryberg (Eds.), 7th International Conference on Networked Learning. Aalborg, Denmark. 
(2014). Epistemology, Assessment, Pedagogy: Where Learning Meets Analytics in the Middle Space. Journal of Learning Analytics, 1(2), $23-47$.

Hofer, B. K. (2001). Personal epistemology research: Implications for learning and teaching. Educational Psychology Review, 13(4), 353-383.

Hopmann, S. T., Brinek, G., \& Retzl, M. (Eds.). (2007). PISA according to PISA: Does PISA keep what it promises? Vienna, Austria: Wien Lit-Verlag. Retrieved from http://www.univie.ac.at/pisaaccordingtopisa/

Huffman, S. B., \& Hochster, M. (2007). How well does result relevance predict session satisfaction? Proceedings of the 30th Annual International ACM SIGIR Conference on Research and Development in Information Retrieval (p. 574). doi:10.1145/1277741.1277839

Katz, S. (2000). Competency, epistemology and pedagogy: Curriculum's holy trinity. Curriculum Journal, 11(2), 133-144. doi:10.1080/09585170050045164

Kelly, G. J., Luke, A., \& Green, J. (2008). What counts as knowledge in educational settings: Disciplinary knowledge, assessment, and curriculum. Review of Research in Education, 32(1), vii-x. doi:10.3102/0091732X07311063

King, P. M., \& Kitchener, K. S. (2004). Reflective judgment: Theory and research on the development of epistemic assumptions through adulthood. Educational Psychologist, 39(1), 5-18. doi:10.1207/s15326985ep3901_2

Kuhn, D., \& Weinstock, M. (2002). What is epistemological thinking and why does it matter? In B. K. Hofer \& P. Pintrich R. (Eds.), Personal epistemology: The psychology of beliefs about knowledge and knowing (pp. 121-144). Mahwah, NJ: Lawrence Erlbaum Associates.

Lazonder, A. W. (2005). Do two heads search better than one? Effects of student collaboration on web search behaviour and search outcomes. British Journal of Educational Technology, 36(3), 465475. doi:10.1111/j.1467-8535.2005.00478.x

Lin, C., \& Tsai, C. (2008). Exploring the structural relationships between high school students' scientific epistemological views and their utilization of information commitments toward online science information. International Journal of Science Education, 30(15), 2001-2022. doi:10.1080/09500690701613733

Maloney, J., Resnick, M., Rusk, N., Silverman, B., \& Eastmond, E. (2010). The scratch programming language and environment. ACM Transactions on Computing Education, 10: Article No. 16.

Mason, L., Ariasi, N., \& Boldrin, A. (2011). Epistemic beliefs in action: Spontaneous reflections about knowledge and knowing during online information searching and their influence on learning. Learning and Instruction, 21(1), 137-151. doi:10.1016/j.learninstruc.2010.01.001

Mason, L., Boldrin, A., \& Ariasi, N. (2009). Epistemic metacognition in context: Evaluating and learning online information. Metacognition and Learning, 5(1), 67-90. doi:10.1007/s11409-009-9048-2

Mercer, N., \& Littleton, K. (2007). Dialogue and the development of children's thinking: A sociocultural approach (New edition.). London: Routledge.

Novak, J. D. (1998). Learning, creating, and using knowledge: Concept maps as facilitative tools in schools and corporations. Mahwah, NJ: Lawrence Erlbaum Associates.

Oliver, M. (2011). Technological determinism in educational technology research: Some alternative ways of thinking about the relationship between learning and technology. Journal of Computer Assisted Learning, 27(5), 373-384. doi:10.1111/j.1365-2729.2011.00406.x 
Olson, D. R., \& Bruner, J. S. (1996). Folk psychology and folk pedagogy. The handbook of education and human development.. In D. R. Olson and N. Torrance (Eds). Blackwell Publishing, 1998. Blackwell Reference Online. 03 June 2014 <http://www.blackwellreference.com/subscriber/tocnode.html?id=g9780631211860_chunk_g9 7806312118604>

Österholm, M. (2009). Theories of epistemological beliefs and communication: A unifying attempt. Proceedings of the 33rd Conference of the International Group for the Psychology of Mathematics Education (Vol. 4, pp. 275-264). Retrieved from http://umu.divaportal.org/smash/record.jsf?pid=diva2:228322

Österholm, M. (2010). Relationships between epistemological beliefs and properties of discourse: Some empirical explorations. In C. Bergsten, E. Jablonka, \& T. Wedege (Eds.), Madif 7, the 7th Swedish Mathematics Education Research Seminar, Stockholm, Sweden (pp. 241-250). Linköping, Sweden: SMDF. Retrieved from http://osterholm.pcriot.com/publ-madif7a.shtml

Potter, J., \& Edwards, D. (2003). Sociolinguistics, cognitivism and discursive psychology. IJES, International Journal of English Studies, 3(1), 93-110.

Säljö, R. (1999). Learning as the use of tools: A sociocultural perspective on the human-technology link. In K. Littleton \& P. Light (Eds.), Learning with computers: Analysing productive interaction. Oxford, UK: Psychology Press.

Säljö, R. (2012). Literacy, digital literacy and epistemic practices: The co-evolution of hybrid minds and external memory systems. Nordic Journal of Digital Literacy, 1, 5-19.

Salomon, G. (1996). Distributed cognitions: Psychological and educational considerations. Cambridge, UK: Cambridge University Press.

Scardamalia, M., \& Bereiter, C. (1993). Technologies for knowledge-building discourse. Communications of the $A C M, 36,37-41$.

Scherr, R. E., \& Hammer, D. (2009). Student behavior and epistemological framing: Examples from collaborative active-learning activities in physics. Cognition and Instruction, 27(2), 147-174. doi:10.1080/07370000902797379

Scheuer, O., Loll, F. N., \& McLaren, B. M. (2010). Computer-supported argumentation: A review of the state of the art. International Journal of Computer-Supported Collaborative Argumentation, 5, 43-102.

Schommer, M. (1990). Effects of beliefs about the nature of knowledge on comprehension. Journal of Educational Psychology, 82(3), 498-504. doi:10.1037/0022-0663.82.3.498

Schraw, G. (2013). Conceptual integration and measurement of epistemological and ontological beliefs in educational research. ISRN Education. Retrieved from http://www.hindawi.com/isrn/education/aip/327680/

Shaffer, D. W., Hatfield, D., Svarovsky, G. N., Nash, P., Nulty, A., Bagley, E., Franke, K., Rupp, A. A., \& Mislevy, R. (2009). Epistemic network analysis: A prototype for 21st century assessment of learning. The International Journal of Learning and Media, 1, 33-53.

Siegel, H. (1998). Knowledge, truth and education. In D. Carr (Ed.), Education, knowledge, and truth: Beyond the postmodern impasse (pp. 19-36). London, UK: Routledge. 
(2014). Epistemology, Assessment, Pedagogy: Where Learning Meets Analytics in the Middle Space. Journal of Learning Analytics, 1(2), $23-47$.

Siemens, G. (2006). Knowing Knowledge. Lulu.com. See www.elearnspace.org/KnowingKnowledge_LowRes.pdf

Simsek, D., Buckingham Shum, S., Sándor, Á., De Liddo, A., \& Ferguson, R. (2013). XIP dashboard: Visual analytics from automated rhetorical parsing of scientific metadiscourse. 1st International Workshop on Discourse-Centric Learning Analytics, at 3rd International Conference on Learning Analytics \& Knowledge. Apr. 8-12, 2013, Leuven, Belgium. Open Access Eprint: http://oro.open.ac.uk/37391

Stadtler, M., \& Bromme, R. (2007). Dealing with multiple documents on the WWW: The role of metacognition in the formation of documents models. International Journal of ComputerSupported Collaborative Learning, 2(2), 191-210. doi:10.1007/s11412-007-9015-3

Suthers, D. D., \& Verbert, K. (2013). Learning analytics as a "middle space." Proceedings of the Third International Conference on Learning Analytics and Knowledge (pp. 1-4). New York: ACM. doi:10.1145/2460296.2460298

Suthers, D. D., Weiner, A., Connelly, J., \& Paolucci, M. (1995). Belvedere: Engaging students in critical discussion of science and public policy issues. In Greer J (Ed.), Proceedings of Al-ED 95: World Conference on Artificial Intelligence in Education. Washington, D.C.: AACE, 266-273.

Tsai, C. (2004). Beyond cognitive and metacognitive tools: The use of the Internet as an "epistemological" tool for instruction. British Journal of Educational Technology, 35(5), 525-536. doi:10.1111/j.0007-1013.2004.00411.x

Tsai, M.-J., \& Tsai, C.-C. (2003). Information searching strategies in web-based science learning: The role of Internet self-efficacy. Innovations in Education \& Teaching International, 40(1), 43-50. doi:10.1080/1355800032000038822

UAGU (2010). Undervisningsministerie (Ministry of Education), \& Afdelingen for Gymnasiale Uddannelser (Department of Secondary Education). (2010, September). Endelig rapport fra følgegruppen for forsøget med digitale prøver med adgang til internettet i udvalgte fag på stx og hhx (Final report of the Monitoring Group experiment with digital samples with access to Internet in selected subjects at stx and HHX). Undervisningsministerie (Ministry of Education). Retrieved from http://www.uvm.dk/ /media/Files/Udd/Gym/PDF10/101007_it_rapport_13\%20september\%20 2010.ashx

Williams, K. (1998). Assessment and the challenge of scepticism. In D. Carr (Ed.), Education, knowledge, and truth: Beyond the postmodern impasse. London, UK: Routledge. 